\title{
Battery Recharging Issue for a Two-Power-Level Flywheel System
}

\author{
Janaína Gonçalves de Oliveira and Hans Bernhoff \\ Division for Electricity, Department of Engineering Sciences, Uppsala University, Box 534, 75121 Uppsala, Sweden \\ Correspondence should be addressed to Janaína Gonçalves de Oliveira, janaina.goncalves@angstrom.uu.se
}

Received 11 February 2010; Revised 19 May 2010; Accepted 9 July 2010

Academic Editor: Henry S. H. Chung

Copyright () 2010 J. Gonçalves de Oliveira and H. Bernhoff. This is an open access article distributed under the Creative Commons Attribution License, which permits unrestricted use, distribution, and reproduction in any medium, provided the original work is properly cited.

\begin{abstract}
A novel battery recharging system for an all-electric driveline comprising a flywheel with a permanent magnet double wound synchronous machine (motor/generator) is presented. The double winding enables two voltage levels and two different power levels. This topology supersedes other all-electric drivelines. The battery operates in a low-power regime supplying the average power whereas the flywheel delivers and absorbs power peaks, which are up to a higher order of magnitude. The topology presents new challenges for the power conversion system, which is the focus of this investigation. The main challenge is the control of the power flow to the battery when the vehicle is parked despite the decay of the flywheel machine voltage; which is dependent on its charge state, that is, rotational speed. The design and simulation of an unidirectional DC/DC buck/boost converter for a variable rotational speed flywheel is presented. Conventional power electronic converters are used in a new application, which can maintain a constant current or voltage on the battery side. Successful PI current control has been implemented and simulated, together with the complete closed loop system.
\end{abstract}

\section{Introduction}

Electric vehicles (EVs) have recently become a more attractive option over combustion engine-based vehicles, because of high fuel prices and environmental concerns. Flywheel systems have shown to be a promising technology for energy storage [1], mainly due to the flywheel's high power and energy densities. Moreover, their weak dependence on charge and discharge cycle rates provides competitive advantages over other technologies, for example, batteries and supercapacitors. However, the combination of flywheels and batteries applied to vehicles can mitigate drawbacks such as power limitation and battery costs.

A maximum energy density of the flywheel rotor close to $200 \mathrm{Wh} / \mathrm{kg}$ has been reported [2]. Currently, commercially usable rotors are limited to approximately $60-80 \mathrm{Wh} / \mathrm{kg}$ [3]. Flywheel systems have the advantages of high-power density and the ability to cope with a very large number of charge-discharge cycles. However, the energy density of the flywheel system is low compared with modern lithiumion battery systems, which can go up to $120 \mathrm{Wh} / \mathrm{kg}$. These properties allow the flywheel to transfer a relatively large amount of energy quickly and repeatedly without reducing its performance. Batteries can therefore be optimized with respect to their energy density.

The battery's charge/discharge cycles have a significant effect on the system performance, playing a critical role for the success of future EVs. Therefore, the batteries should be placed in a topology which allows optimum performance, increasing the utilization time [4].

The proposed system is a two-power-level flywheel energy storage system. The flywheel stator winding has a high-power (HP) side which is connected to wheel motors and a low-power (LP) side which is connected to a main energy source (battery) as seen in Figure 1.

Contrary to other electric vehicle topologies, the battery is not directly connected to the wheel motor; instead, it is separated by the double wound flywheel motor/generator. In this way, the battery is not directly charged at regenerative breaking as the power is absorbed by the flywheel.

The battery can be recharged by the flywheel either when the flywheel speed exceeds a maximum limit during a drive cycle, or when the car is parked and all the stored energy in the flywheel is transferred back into the battery. 


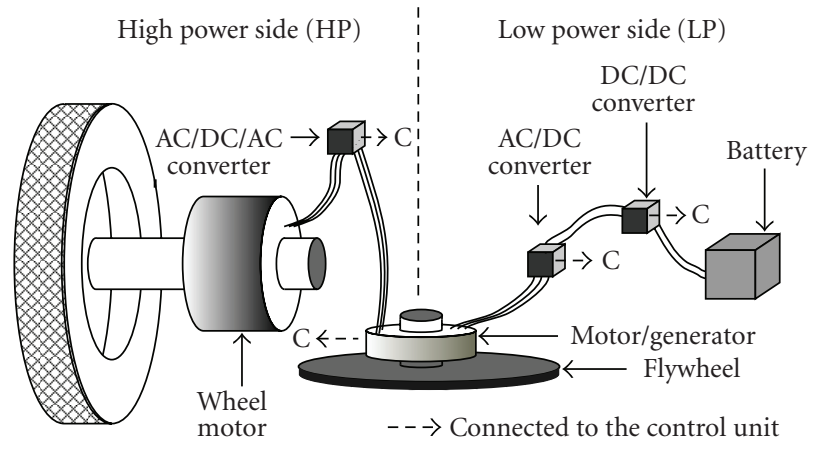

FIGURE 1: EV propulsion system based on a flywheel energy storage device with two power levels.

The present work focuses on the latter case, since the first one rarely occurs when normal urban drive cycles are taken into account [5]. The output voltage of the flywheel machine decreases when it is used to recharge the battery, due to the decreasing rotational speed. To accommodate the voltage difference, a buck/boost converter is used when the flywheel is charging the battery.

This paper is outlined as follows. Section 2 focuses on the recharging process for technologies and applications of battery energy storage, including the present flywheel system. Section 3 introduces the average linear model of the proposed buck/boost chopper and its Proportional-Integral (PI) controller. Section 4 presents the simulation of the LowPower Converter System, when the flywheel works as a generator, focusing on the battery's current/voltage control.

\section{The Flywheel-Battery System}

In EV systems, primary requirements for battery chargers are rapid and efficient charging using equipments as simple as possible, avoiding damage to the battery. There are different methods for charging batteries, but the constant current method requires simple and less expensive control equipment compared with other methods [6].

The charging is arranged in two periods: the bulk charge and the trickle charge. The first charging period is performed at constant current as the battery voltage progressively increases. A constant voltage charging should be applied as soon as the battery voltage reaches the trickle level, which usually occurs when the battery is close to $80 \%$ of the maximum state of charge [7].

Battery charging systems for EVs reported in the literature are generally developed for regenerative braking or grid connection. The battery charging process during regenerative braking requires some sort of step-up circuit, since the back electromotive force of the flywheel machine is lower than the battery voltage. In neighborhood EVs [8] and electric wheel chairs [9] a conventional boost converter is used to achieve regenerative braking. When the battery is charged from the grid, onboard or off-board chargers can be based on step-down or step-up converters, depending on the battery voltage $[10,11]$.
The battery charging systems reported in the literature are based on well-known input sources, which is not the case of the present flywheel system application. The voltagedependent flywheel speed can be anywhere within the full range when the battery recharging process starts. The flywheel speed decreases as energy is being extracted. Therefore, the flywheel output voltage decreases proportionally to the rotational speed.

The initial flywheel output voltage is high for high speeds and a buck DC/DC converter is necessary to control constant current into the battery. A buck converter can be used while the flywheel output voltage is higher than the battery charging voltage. A boost DC/DC converter has to be used to keep the current constant (or constant voltage, depending on the charging period) when the flywheel output voltage is lower than the required battery charging voltage.

Two-quadrant bidirectional converters used for battery charging and discharging control have been reported with the buck converter working in the first quadrant and the boost converter working in the second quadrant [12, 13]. A unidirectional buck/boost converter was designed by Mohan et al. [14], but this topology results in a negative-polarity output with respect to the common terminal of the input voltage, which can not be used for battery charging.

A two-stage unidirectional converter, consisting of a buck and a boost regulator connected in series is proposed for stepping-up and/or -down the signal during the battery charging (see Figure 2).

\section{Average Model of Buck/Boost Converter and Its Control Design}

3.1. Principle of Operation. The aim of the buck/boost converter is to control the current and voltage during battery recharging, using the energy stored in the flywheel. The stored energy is sent back to the battery when the vehicle is parked. The flywheel motor/generator is connected to a passive rectifier, as shown in Figure 2. The rectifier output is connected to the unidirectional DC/DC converter. Although connected in series, buck and boost functionality are not used simultaneously in the present application [15]. The converters are connected in series to maintain the current direction, regardless to the operation mode (boost or buck mode).

The unidirectional DC/DC converter can operate over a wide range of input voltages, as shown in Figure 2. The converter can also maximize power transfer, since the boost stage of the converter can provide power factor correction circuitry [11]. The buck stage is used to provide currentcontrolled charging when the input voltage is higher than the battery nominal voltage (e.g., grid charging).

The unidirectional DC/DC converter with combined buck and boost topologies shown in Figure 2 is novel as both converters can work independently. To operate the converter as a buck, S1 is open and S2 is chopping. To operate it as a boost, $\mathrm{S} 1$ is chopping and S2 is conducting. 


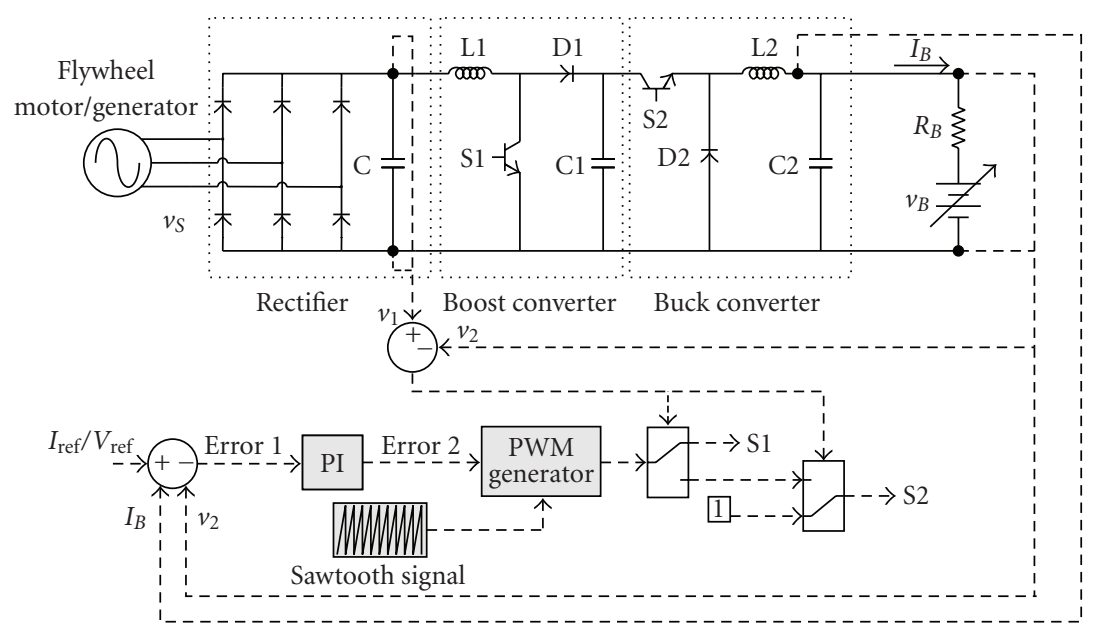

FIgURE 2: Equivalent circuit diagram of the simulated system.

3.2. Controller Design. Constant current/voltage control can be accomplished with a Proportional Integrative (PI) controller by using the buck and boost converter transfer functions in a closed loop system [16]. The proportional gain and the integrative gain are chosen to obtain the desired pole placement and, consequently, the desired rise time and peak overshot of the system response. The step response of the PI closed loop system for the buck converter is illustrated in Figure 3. The step response for the boost converter is shown in Figure 4. Both figures show a short rise time (around 0.02 seconds) and minimal peak overshot (less than 5\%). The Nyquist plot of the buck converter in the PI-controlled closed loop system is shown in Figure 5. The Nyquist Plot of the boost converter in the PI-controlled closed loop system is shown in Figure 6. Both plots give stable responses according to the Nyquist criterion, since the open loop transfer function of the system has no poles with positive real part. The number of poles with negative real part is equal to the number of circles around the $\mathrm{x}$-coordinate " -1 " in the graphs [17].

\section{Simulations}

Simulations are based on the power converter circuit presented in Figure 2. Flywheel AC output voltage is passively rectified. The DC output voltage of the rectifier is fed to the DC/DC converter. The converter operation mode (buck/boost) is activated after comparing the rectified input voltage to the battery voltage. Henceforth, buck or boost switch control is chosen. The control compares the load current with the reference current during the first charging period. The PI controller minimizes the error between a measured current and a desired set point. The output is compared to a saw tooth source to generate the pulses that polarize the switch S1 or S2. The duty cycle changes depending on the PI controller output signal and fix the load current to the reference, independent of the input signal. During the second charging period, battery charging voltage is desired to be constant instead of battery current. At this

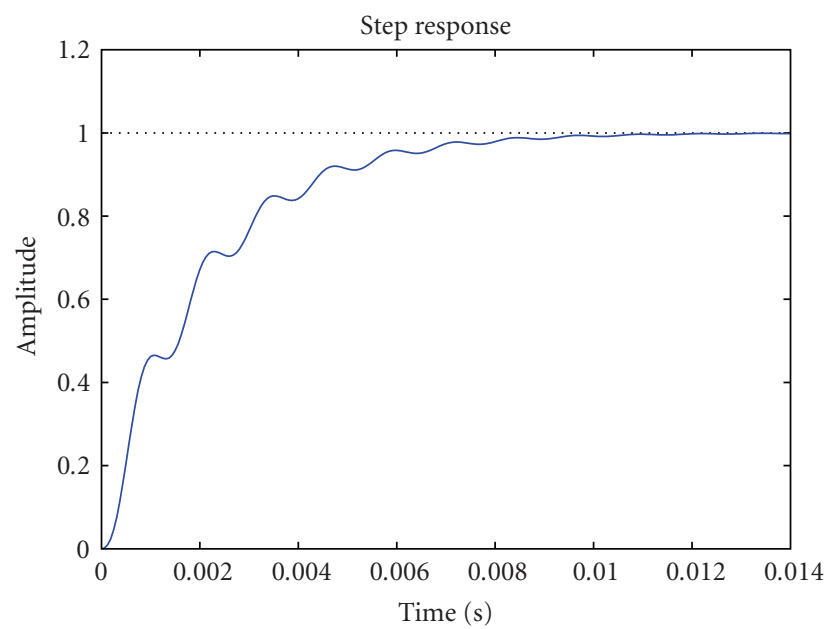

FIgure 3: Closed loop buck converter step response.



FIgURE 4: Closed loop boost converter step response. 


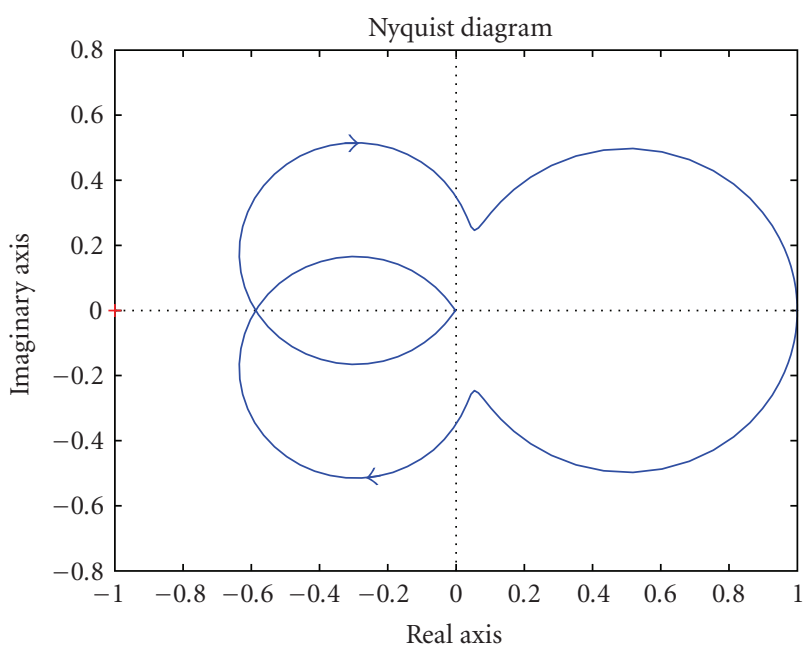

FIGURE 5: Nyquist plot of the closed loop buck converter.

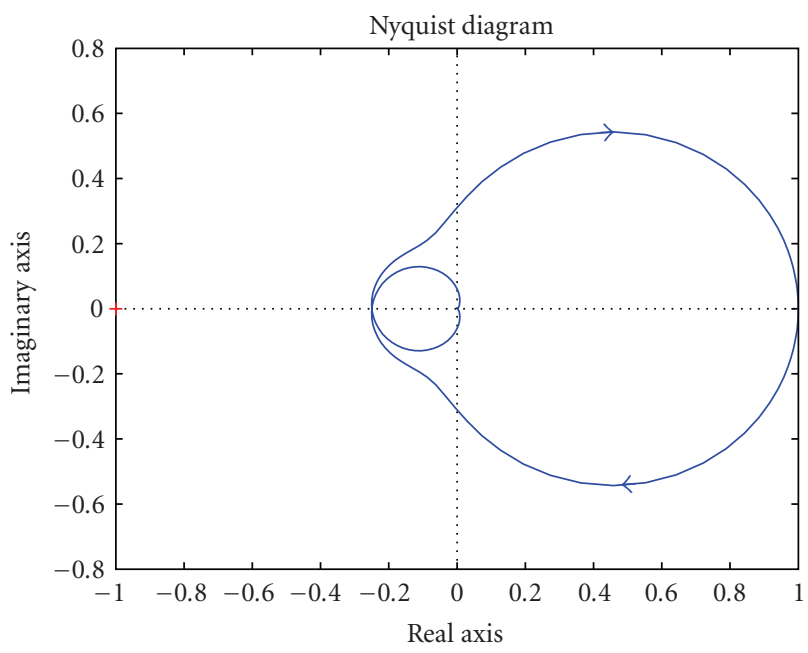

FIGURE 6: Nyquist plot of the closed loop boost converter.

stage, as for the first charging period, a measured voltage and a desired set point are compared and controlled by means of the PI controller.

4.1. Simulation Results. A three-phase flywheel permanent magnet machine has been simulated. Simulation conditions are given in Table 1. Values of $L$ and $C$ were chosen to $100 \mu \mathrm{H}$ and $200 \mu \mathrm{F}$ to minimize ripple in the output voltage since both converters operate in continuous conduction mode. The switching frequency was set to $10 \mathrm{kHz}$. Battery charging current and voltage presented in Table 1 are typical values for low-power lithium-ion batteries. The battery internal resistance $R_{B}$ was assumed to be $1 \Omega$.

Due to the computational limitations, the simulation time was scaled to a more suitable value which can be handled with a regular computer. The scaled simulation time also forces the control to operate in extreme conditions, since in a regular charging cycle the acceptable response time is larger.
TABle 1: Parameters of the system used in the DC/DC converter simulation.

\begin{tabular}{lc}
\hline Flywheel machine initial speed & $6000 \mathrm{RPM}$ \\
Flywheel machine initial output phase voltage & $42 \mathrm{~V}$ \\
Battery type & Lithium-Ion \\
Battery Voltage Range & $25-42 \mathrm{~V}$ \\
Charging current & $1.9 \mathrm{~A} \pm 0.1 \mathrm{~A}$ \\
\hline
\end{tabular}

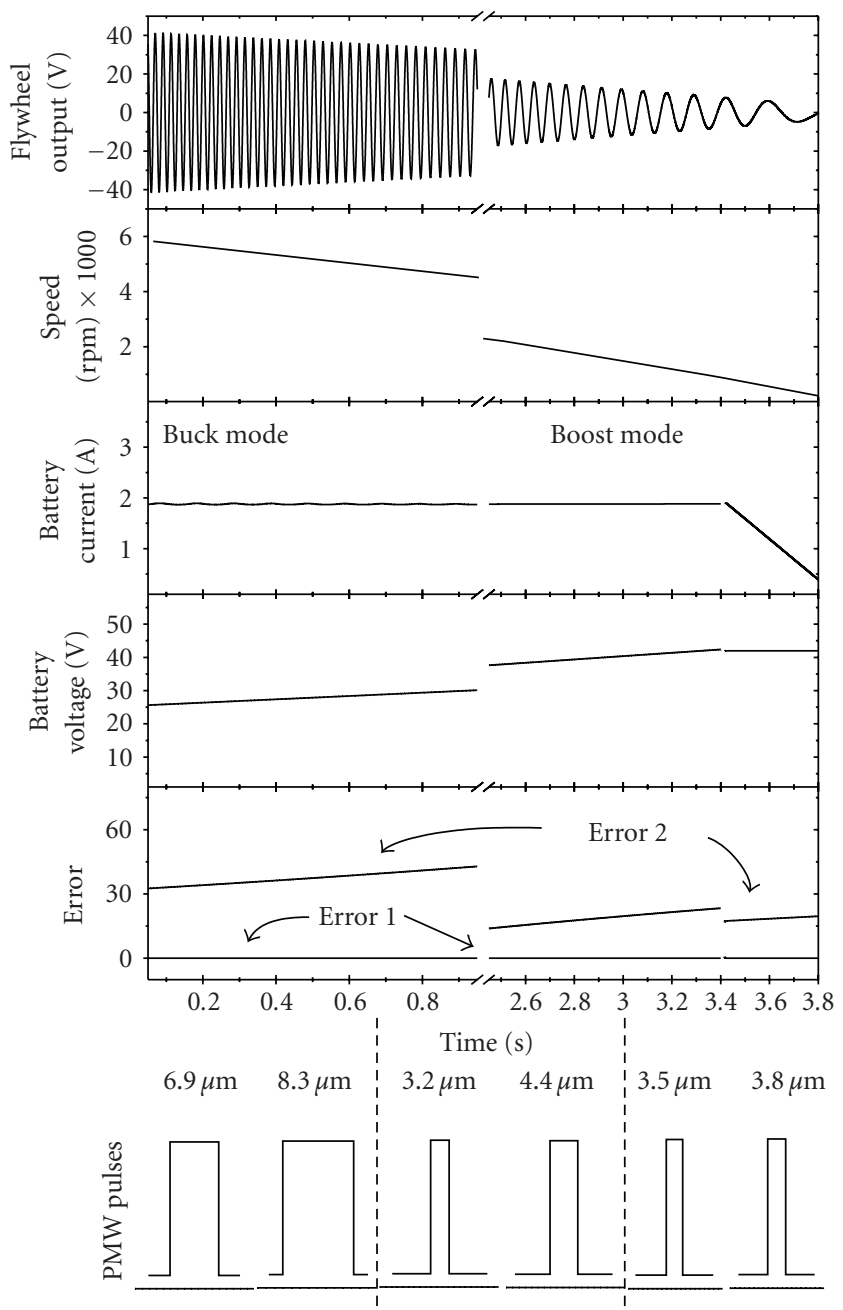

FIGURE 7: Battery current, voltage, control errors, and PWM pulses during buck and boost operation modes.

The battery charging simulation results are shown in Figure 7. The simulation started with the battery close to a discharged state, corresponding to $25 \mathrm{~V}$. Initially, the control operates the system in buck mode, since the flywheel output voltage is higher than the battery voltage (see Table 1), followed by the boost operation mode. At $1.2 \mathrm{~s}$ the flywheel machine output voltage becomes equal to the battery voltage. The battery has reached its nominal voltage of $42 \mathrm{~V}$ after 3.4 seconds. Input voltage is then kept constant (at $42 \mathrm{~V}$ ) and charge current starts to drop as full charge is approached. 
Full charge is reached when battery current is less than 3\% of the rated current $(1.9 \mathrm{~A})$. The machine stops rotating after $4 \mathrm{~s}$ when the battery has reached $100 \%$ of its total charge.

Flywheel machine output voltage, flywheel rotational speed, battery current, battery voltage, and current error after the first comparator and the error after the PI controller (Error 1 and 2) are shown in Figure 7. The lowest panel presents the PWM pulses. The results are shown for the first second of buck operation, followed by the corresponding data of boost operation and constant voltage period.

The Error 1 voltage varies around zero, since the actual current has been kept equal to the reference current, as seen in Figure 7. The Error 2 increases as a function of the PI controller proportional gain and changes the PWM duty cycle, allowing the switch to be opened for longer periods of times. The longer pulses can be seen at the end of each converter operation interval.

The simulations include losses in the passive components (inductors and capacitors) and in the battery model, given that the present DC/DC converter has a two-stage filter, increasing the number of passive components in the system. The inductors' and capacitors' internal series resistance (ESR) were set to $5 \mathrm{~m} \Omega$. Ideal switches were used during the simulation. An efficiency of $92 \%$ was obtained after calculating the input power in capacitor $C$ (Figure 2) and the output power over the battery.

\section{Conclusions and Discussion}

A battery charger converter system for a two-power-level flywheel system containing a passive rectifier and a DC/DC converter has been presented. The designed converter stability was evaluated through simulations under closed loop control. The proposed PI controller is capable of keeping a constant current or voltage during battery charging with a low ripple during buck and boost operation. The simulation indicates that the control is robust enough to allow battery recharging despite the decrease in the flywheel output voltage when slowing down. The battery recharging within the present flywheel system can also be combined to a charging process from the grid by using the same DC/DC converter.

\section{References}

[1] R. Hebner, J. Beno, A. Walls, and M. J. Riezenman, "Flywheel batteries come around again," IEEE Spectrum, vol. 39, no. 4, pp. 46-51, 2002.

[2] G. Genta, Kinetic Energy Storage: Theory and Practice of Advanced Flywheel Systems, Butterworth-Heinemann, London, UK, 1985.

[3] K. Takahashi, S. Kitade, and H. Morita, "Development of high speed composite flywheel rotors for energy storage systems," Advanced Composite Materials, vol. 11, no. 1, pp. 40-49, 2001.

[4] S.-K. Sul and S.-J. Lee, "Integral battery charger for fourwheel drive electric vehicle," IEEE Transactions on Industry Applications, vol. 31, no. 5, pp. 1096-1099, 1995.

[5] J. Santiago, J. G. Oliveira, J. Lundin, J. Abrahamsson, A. Larsson, and H. Bernhoff, "Design parameters calculation of a novel driveline for electric vehicles," World Electric Vehicle Journal, vol. 3, 2009.
[6] L. Solero, "Nonconventional on-board charger for electric vehicle propulsion batteries," IEEE Transactions on Vehicular Technology, vol. 50, no. 1, pp. 144-149, 2001.

[7] S. Dearborn, "Charging Li-ion batteries for maximum run times," Power Electronics Technology, vol. 31, no. 4, pp. 40-49, 2005.

[8] C. Binggang, B. Zhifeng, and Z. Wei, "Research on control for regenerative braking of electric vehicle," in Proceedings of IEEE International Conference on Vehicular Electronics and Safety, pp. 92-97, October 2005.

[9] K. Takahashi, H. Seki, and S. Tadakuma, "Safety driving control for electric power assisted wheelchair based on regenerative brake," in Proceedings of IEEE International Conference on Industrial Technology (ICIT'06), pp. 2492-2497, December 2006.

[10] M. Bojrup, P. Karlsson, M. Alakula, and B. Simonsson, "A dual purpose battery charger for electric vehicles," in Proceedings of the 29th Annual IEEE Power Electronics Specialists Conference, vol. 1, pp. 565-570, 1998.

[11] B. J. Masserant and T. A. Stuart, "A maximum power transfer battery charger for electric vehicles," IEEE Transactions on Aerospace and Electronic Systems, vol. 33, no. 3, pp. 930-938, 1997.

[12] D. M. Sable, F. C. Lee, and B. H. Cho, "A zero-voltageswitching bidirectional battery charger/discharger for the NASA EOS Satellite," in Proceedings of the 7th Annual Applied Power Electronics Conference and Exposition, pp. 614-621, 1992.

[13] X. Yan, A. Seckold, and D. Patterson, "Development of a zero-voltage-transition bidirectional DC-DC converter for a brushless DC machine EV propulsion system," in Proceedings of the 33rd IEEE Annual Power Electronics Specialists Conference (PESC'02), pp. 1661-1666, June 2002.

[14] N. Mohan, T. M. Undeland, and W. P. Robbins, Power Electronics. Converters, Applications and Design, John Wiley \& Sons, New York, NY, USA, 2nd edition, 1995.

[15] Y. C. Chuang and Y. L. Ke, "High efficiency battery charger with a buck zero current switching PWM converter," IET Power Electronics, vol. 1, pp. 433-444, 2008.

[16] R. W. Eriksson, "DC/DC Power Converters," in Wiley Encyclopedia of Electrical and Electronics Engineering, WileyInterscience, New York, NY, USA.

[17] A. Tewari, Modern Control Design with Matlab and Simulink, John Willey \& Sons, New York, NY, USA, 2005. 

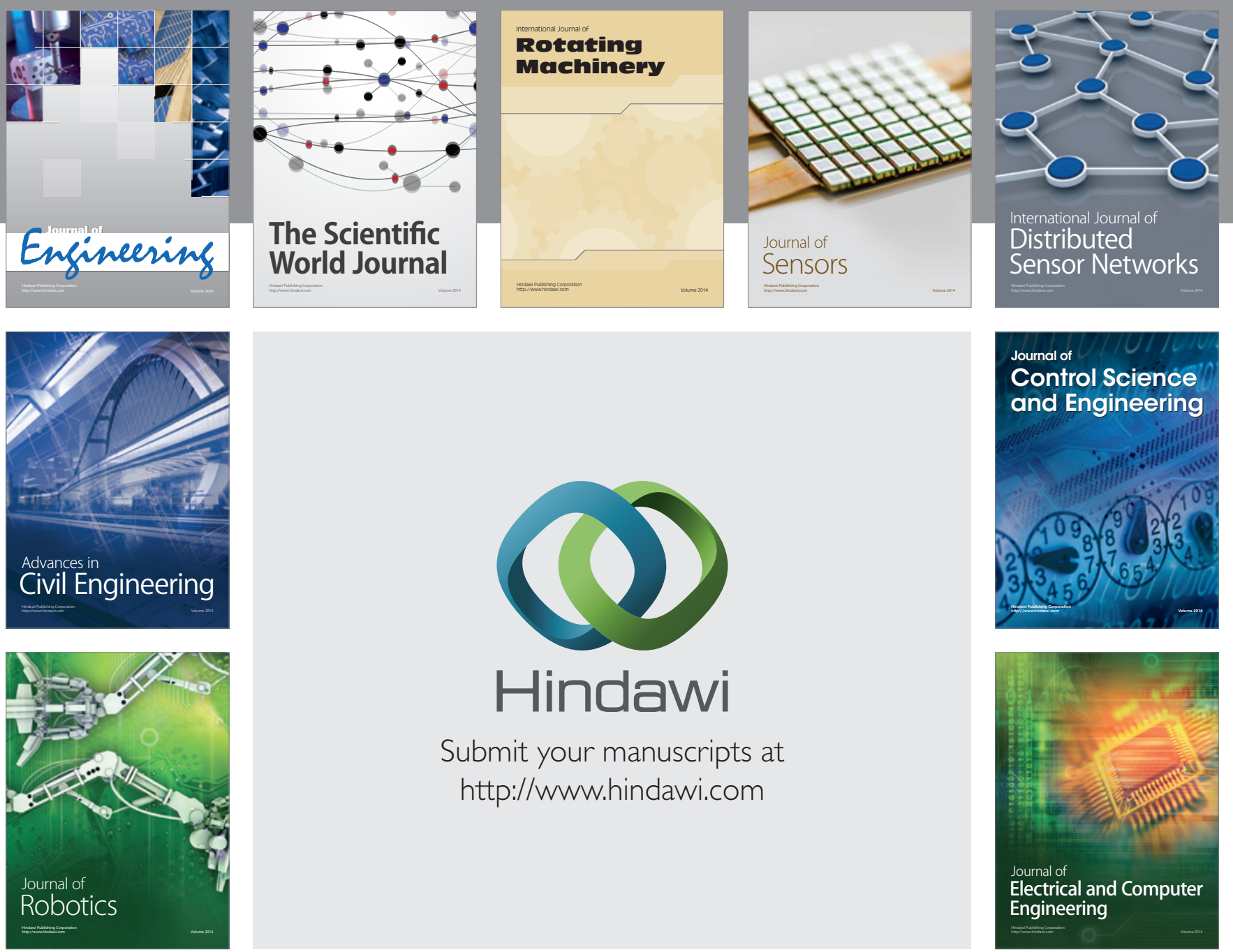

Submit your manuscripts at

http://www.hindawi.com
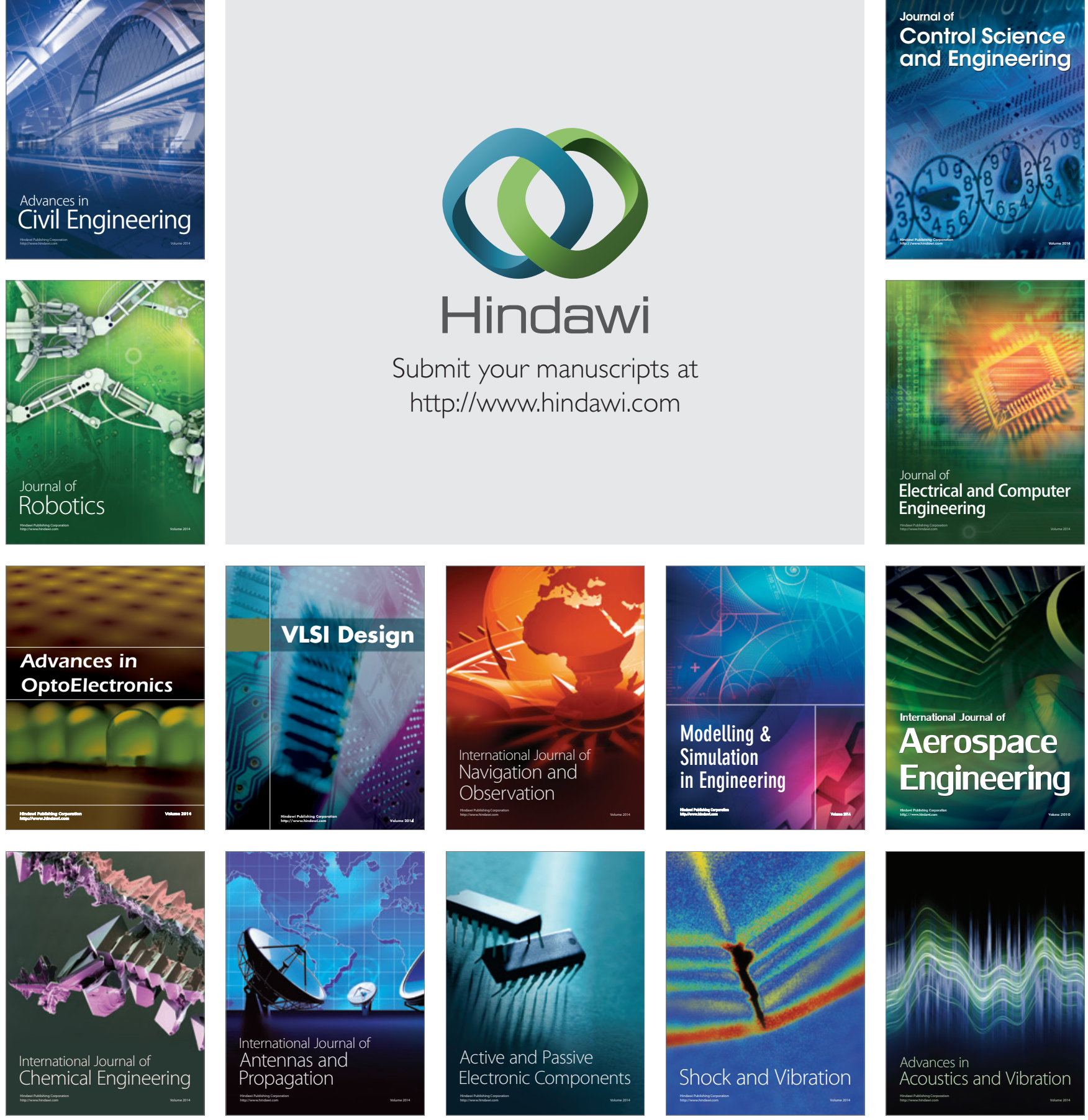